This document is the accepted manuscript version of the following article:

Blocken, B., \& Carmeliet, J. (2015). Impact, runoff and drying of wind-driven rain on a window glass

surface: numerical modelling based on experimental validation. Building and Environment, 84, $170-180$. https://doi .org/10.1016/j.bui1denv.2014.11.006

This manuscript version is made available under the CC-BY-NC-ND 4.0 1icense

http://creativecommons.org/1icenses/by-nc-nd/4.0/

\title{
Impact, runoff and drying of wind-driven rain on a window glass surface: numerical modelling based on experimental validation
}

\author{
B. Blocken* ${ }^{(a, b)}$, J. Carmeliet ${ }^{(c, d)}$ \\ (a) Building Physics and Services, Department of the Built Environment, Eindhoven University of \\ Technology, P.O. box 513, 5600 MB Eindhoven, The Netherlands \\ (b) Division of Building Physics, Department of Civil Engineering, Leuven University, Kasteelpark \\ Arenberg 40 - box 2447, 3001 Leuven, Belgium \\ (c) Laboratory for Building Science and Technologies, Swiss Federal Laboratories for Materials Testing and \\ Research, Empa, Überlandstrasse 129, CH-8600 Dübendorf, Switzerland \\ (d) Chair of Building Physics, Swiss Federal Institute of Technology ETHZ, ETH-Hönggerberg, CH-8093 Zürich, \\ Switzerland
}

\begin{abstract}
This paper presents a combination of two models to study both the impingement and the contact and surface phenomena of rainwater on a glass window surface: a Computational Fluid Dynamics (CFD) model for the calculation of the distribution of the wind-driven rain (WDR) across the building facade and a semi-empirical droplet-behaviour model. The CFD model comprises the calculation of the wind-flow pattern, the raindrop trajectories and the specific catch ratio as a measure of the WDR falling onto different parts of the facade. The droplet-behaviour model uses the output of the CFD model to simulate the behaviour of individual raindrops on the window glass surface, including runoff, coalescence and drying. The models are applied for a small window glass surface of a two-storey building. It is shown that by far not all WDR that impinges on a glass surface runs off, due to evaporation of drops adhered to the surface. The reduction of runoff by evaporation is $26 \%$ for a typical cumuliform rain event and $4 \%$ for a typical stratiform rain event. These models can be used to provide the knowledge about WDR impact, runoff and evaporation that is needed for the performance assessment of selfcleaning glass or the study of the leaching of nanoparticles from building facades.
\end{abstract}

Keywords: Wind-driven rain; driving rain; wind flow; runoff; raindrop; drying.

\section{Introduction}

Wind-driven rain (WDR) is one of the most important moisture sources affecting the hygrothermal performance and the durability of building facades (e.g. [1,2]). Consequences of its destructive properties can take many forms. Moisture accumulation in porous materials can lead to water penetration, moisture induced salt migration, discolouration by efflorescence, structural cracking due to thermal and moisture gradients, to mention just a few. WDR impact and runoff are also responsible for the appearance of other types of surface soiling patterns on facades that have become characteristic for so many of our buildings (e.g. [1,2]). Other types of WDR related problems include the self-cleaning action of glass combined with runoff [3] and the leaching of nanoparticles from surface coatings and biocides from facades [4-6].

In building physics, two parts of WDR research can be distinguished [2]: (1) assessment of the impinging WDR intensity (Fig. 1a) and (2) assessment of the response of the building facade to the impinging WDR (Fig. 1b). The impinging WDR intensity is the total amount of rainwater that comes into contact with the building surface. What happens at and after impact/impingement is the focus of the second part of WDR research. It comprises the study of contact and surface phenomena such as splashing, bouncing, adhesion, runoff, evaporation, absorption and the distribution of the moisture in the facade (rain penetration and wetting-drying). It also includes the wide variety of rainwater penetration mechanisms such as hydrostatic pressure, wind pressure, surface tension and gravity.

Most WDR research in building physics in the past has focused on the first part. An extensive review of this part of WDR research was provided by Blocken and Carmeliet [2], in which three assessment methods were distinguished: measurements, semi-empirical formulae and numerical simulations based on Computational Fluid

\footnotetext{
* Corresponding author: Bert Blocken, Building Physics and Services, Eindhoven University of Technology, P.O.Box 513, 5600 MB Eindhoven, the Netherlands. Tel.: +31 (0)40 247 2138, Fax +31 (0)40243 8595

E-mail address: b.j.e.blocken@tue.nl
} 
Dynamics (CFD). In the past 10 years, also more recent reviews on this first part of WDR research have been published [7-10]. Research on the first part of WDR is still fully ongoing, as evidenced by many recent publications in Building and Environment and other journals (e.g. [11-14]).

The second part in WDR research however has received much less attention. Although a very large number of studies focused on heat, air and moisture (HAM) transfer in building components, only relatively few of them focused in detail on WDR as a boundary condition (e.g. [15-22]). Abuku et al. in 2008 [17] focused on contact and surface phenomena such as spreading, splashing and bouncing on vertical building surfaces. Straube [18] extensively discussed rainwater penetration mechanisms including hydrostatic pressure, wind pressure, surface tension and gravity. Several authors performed studies of rainwater runoff on building facades [19-22]. An extensive review on rainwater runoff from building facades can be found in [23].

This paper presents an attempt to bridge the gap between the two parts in WDR research. It combines existing and new models for the study of the impingement and behaviour of raindrops on an impervious, smooth, vertical surface. In section 2, the CFD model used to calculate the WDR impingement is described. In section 3, the different sub-models of the droplet-behaviour model (including drop distribution, runoff and evaporation) are outlined. Section 4 presents the application of these models for a case study: WDR on a window glass surface in the facade of a two-storey building. Sections 5 (discussion) and 6 (conclusions) conclude the paper.

\section{CFD model for wind-driven rain impingement}

\subsection{Model description}

The CFD model for WDR is based on the model by Choi [24] and on the extension and validation of this model by Blocken and Carmeliet [25,26]. This model can provide the spatial and temporal distribution of WDR on a building facade. Here, it is used to calculate the specific catch ratio for different positions at the building facade. For every raindrop diameter $\mathrm{d}$, the specific catch ratio is defined as:

$$
\eta_{d}=\frac{S_{w d r}(d)}{S_{h}(d)}
$$

where $S_{w d r}(d)$ is the specific WDR amount on the building facade comprised of raindrops with diameter $d$ (in $\mathrm{L} / \mathrm{m}^{2}$ or $\mathrm{mm}$ ) and $\mathrm{S}_{\mathrm{h}}(\mathrm{d})$ is the specific horizontal rainfall amount comprised of raindrops with diameter d (i.e. unobstructed rainfall through a horizontal plane; in $\mathrm{L} / \mathrm{m}^{2}$ or $\mathrm{mm}$ ). The procedure to obtain the specific catch ratio consists of three steps:

1. Simulation of the steady-state 3D wind-flow pattern around the building with the Reynolds-averaged NavierStokes (RANS) equations and the realizable k- $\varepsilon$ turbulence model by Shih et al. [27].

2. Calculation of raindrop trajectories by injecting raindrops in the calculated wind-flow field and by solving their equations of motion by Lagrangian particle tracking. This is done for different values of the reference wind speed $U_{10}(\mathrm{~m} / \mathrm{s}$ at $10 \mathrm{~m}$ height $)$, the wind direction $\varphi_{10}\left({ }^{\circ}\right.$ from north $)$ and for the entire range of raindrop diameters $(\mathrm{d}=0.3$ to $6 \mathrm{~mm})$.

3. Determining the specific catch ratio for each raindrop diameter from the geometrical configuration of the raindrop trajectories.

The specific catch ratio is calculated for different positions on the building facade, for different values of the reference wind speed $U_{10}$ and wind direction $\varphi_{10}$. It is typically presented in a set of charts, displaying $\eta_{d}$ as a function of $U_{10}$ and $d$ for a given position and a given wind direction (Fig. 2).

\subsection{Model validation}

The CFD model has been validated on several occasions in the past. Because of the importance of validation and for completeness of the present paper, a selection of results from one of these earlier validation studies [26] is briefly reproduced here. This study was performed for the isolated low-rise VLIET test building at Leuven University in Flanders, Belgium (Fig. 3). South-west of the building, some low-rise agricultural construction and a row of trees were situated (Fig. 4). Detailed measurements of approach-flow wind speed $\mathrm{U}_{10}$, wind direction $\varphi_{10}$, horizontal rainfall intensity $R_{h}(\mathrm{~mm} / \mathrm{h})$ and WDR intensities $(\mathrm{mm} / \mathrm{h})$ on the south-west building facade were obtained by a measurement set-up that was specifically designed for CFD validation (Fig. 3, 5). The WDR intensities were measured with WDR gauges that were specifically devised by the authors for accurate WDR measurements [28]. The details of the measurement set-up can be found in [29]. WDR measurements were performed at 20 positions across the south-west facade (Fig. 3). 
The information on the specific catch ratio resulting from the three-step procedure outlined in section 2.1 can be combined with a model raindrop spectrum [30] and finally with the meteorological data for the rain event. The meteorological data consists of 10-minute values of wind speed, wind direction and horizontal rainfall intensity. The combination of all this information then allows to calculate the WDR intensity on the building facade in space and time. Fig. 6a depicts the meteorological data of a given rain event, which is a cumuliform rain event that is composed of a few rain showers. In this case, the most intensive showers occur at the end of the rain event. The total horizontal rainfall amount $\mathrm{S}_{\mathrm{h}}=15.7 \mathrm{~mm}$. The wind direction during rain is approximately south-west $\left(225^{\circ}\right)$, i.e. perpendicular to the facade in Fig. 3. Fig. $6 \mathrm{~b}$ shows the calculated and measured temporal distribution of cumulative WDR at gauge position 13, indicating a close agreement. The absolute WDR measurement error is estimated following the procedure outlined in [28,29]: $\mathrm{E}_{\mathrm{wdr}}=0.8 \mathrm{~mm}$. The spatial distribution of WDR for the rain event is given in Fig. 7, by means of the ratio of total WDR amount $S_{w d r}$ for the rain event divided by total horizontal rainfall amount $S_{h}=15.7 \mathrm{~mm}$. Figs. 7a-b illustrate the numerical results. Fig. $7 \mathrm{~b}$ additionally shows the calculated values at the positions of the WDR gauges. Fig. 7c holds the measurement results. The WDR measurement error estimate for the ratio $\mathrm{S}_{\mathrm{wdr}} / \mathrm{S}_{\mathrm{h}}$ is $\mathrm{e}_{\mathrm{wdr}}=0.05$. The black areas indicate those parts of the facade that are sheltered from rain by the roof overhang. Generally, the agreement between numerical and experimental results is good. The numerical simulation provides a good indication of the distinct wetting pattern across the facade, with the flat-roof module building facade receiving significantly more WDR than the sloped-roof module facade, which is to a large extent caused by the wind-blocking effect that is larger for the sloped-roof module [31]. For all 20 positions, the RMSE (rooth mean square error) is 0.056.

However, some clear overestimations by the numerical model are noted. Large discrepancies (overestimations) are present at the sloped-roof-module corner (positions 2-3). This is attributed to the retarding effect by the row of trees (see Fig. 4) on the wind flow, which is not included in the model but which is present in reality. This row of trees will slow down the wind flow and therefore reduce the WDR intensity near the west corner of the facade. As this effect is not included in the model, the CFD simulations logically overestimate the WDR intensity near this corner. If only positions 4-20 are considered, the RMSE goes down to 0.046.

\section{Semi-empirical model for raindrop behaviour}

The model for drop behaviour consists of three parts or sub-models: (1) a probability-based Monte-Carlo distribution model for the raindrops over the surface; (2) a runoff model; and (3) an evaporation model.

\subsection{Drop distribution model}

The inputs for the distribution model are the geometry of the facade part under study and the meteorological data record (wind speed $U_{10}$, wind direction $\varphi_{10}$, horizontal rainfall amount $S_{h}\left(\mathrm{~mm}\right.$ or L/m${ }^{2}$ ) as a function of time) for the rain event. The part of the facade under study is partitioned into a large number of square zones by a rectangular grid (see example in Fig. 8). The size of the zones is determined by the maximum diameter of a surface-pendent drop before runoff. When a raindrop hits a non-porous, smooth surface like window glazing, it spreads out to form a surface-pendent drop (SPD) with base diameter $\mathrm{d}_{\mathrm{SPD}}$ (see detail A in Fig. 8 and a crosssection in Fig. 9a). Experiments of water spraying on vertical glass surfaces have indicated that the maximum value d' for water drops on such surfaces is about 4-5 $\mathrm{mm}$ [28]. Therefore the size of the square zones in Figure 8 can be taken $5 \mathrm{~mm}$.

The rain event is partitioned into time steps of 10 minutes. For each 10-minute time step i, the meteorological data $\left(\mathrm{U}_{10 \mathrm{i}}, \mathrm{S}_{\mathrm{hi}}, \varphi_{10 \mathrm{i}}\right)$ are used to extract the corresponding specific catch ratio $\eta_{\mathrm{di}}$ from the appropriate specific catch ratio chart (see example in Fig. 2). The 10-minute horizontal rainfall amount $\mathrm{S}_{\mathrm{hi}}\left(\mathrm{in} \mathrm{L} / \mathrm{m}^{2}\right.$ ) is then broken down into a large number of individual raindrops $\mathrm{N}_{\mathrm{hi}}$ (number $/ \mathrm{m}^{2}$ ). This is done using the raindrop-size distribution by Best [30] taking into account the flux modification [2,25]. Figure 10 shows how the raindrop sizes are distributed (in volume fractions) for different horizontal rainfall intensities $\mathrm{R}_{\mathrm{hi}}$. For each zone, the number of raindrops $\mathrm{N}_{\mathrm{hi}}(\mathrm{d})$ of each size $\mathrm{d}$ is then multiplied by the zone area $\left(\mathrm{m}^{2}\right)$ and by the specific catch ratio $\eta_{\mathrm{di}}$ for that zone. This yields the number of raindrops $\mathrm{N}_{\mathrm{wdri}}(\mathrm{d})$ of each diameter arriving at that zone in the 10minute time interval.

Based on this knowledge, a Monte-Carlo simulation is started in which the raindrops, one after the other, are placed in the different zones on the total window surface. The sequence in which the drops of different sizes are attached to different zones is "semi-random". It is a probability-based Monte-Carlo simulation, taking into account the impact probability of each drop of each size at each of the zones. This probability is determined by the specific catch ratio. As such, it simulates "random" wetting on a drop-by-drop basis as would be the case in a real rain event. 


\subsection{Drop runoff model}

A semi-empirical model to simulate the adhesion, coagulation and runoff of raindrops on an impervious, smooth, vertical surface is briefly described below. On contact with a surface, a raindrop spreads out to form a surfacependent drop (see detail A in Fig. 8a). When two raindrops encounter each other, they coagulate to form a larger drop inside the $5 \times 5 \mathrm{~mm}^{2}$ zone. When the raindrop volume or base diameter exceeds a limit value (threshold), the drop runs down, taking all drops that it finds on its vertical path with it and leaving a small trace of tiny droplets behind (see detail B in Fig. 8). The runoff model is based on experimental observations during spraying tests on a vertical glass surface with a plant-sprayer with adjustable nozzle. Every test was repeated at least 20 times, from which average values for the quantities of interest were derived. As already mentioned in section 3.1, it appeared that the maximum base diameter d' of the drop before run-off is fairly constant: 4-5 mm. When runoff occurs, the drops run down fairly straight. The typical base diameter of the trace drops, which are the drops that are left behind along the vertical runoff path, is $1 \mathrm{~mm}$ with a vertical spacing in between of $8-10 \mathrm{~mm}$. A short while after the start of the spraying, the amount of water present as adhesion water on the vertical surface remains approximately constant. At any time, droplets present at the surface as adhesion water are subjected to evaporation.

\subsection{Drop evaporation model}

Droplets present at the vertical surface can be approximated by a spherical cap with base diameter d' (m) and a contact angle $\theta$ (Fig. 9b). When evaporation occurs, the cap shrinks, showing a decrease of the base diameter d'. In this model, the contact angle is assumed to remain approximately constant during evaporation (Fig. 9b). The drying of the drop can be written as:

$$
\begin{aligned}
V(t) & =V_{0}-\frac{1}{\rho_{l}} \int_{0}^{t} \beta p_{v s a t}\left(1-\phi_{e}\right) S(t) d t \\
& =V_{0}-\Delta V(t)
\end{aligned}
$$

with $\mathrm{V}_{0}\left(\mathrm{~m}^{3}\right)$ the initial volume of the drop or cap, $\rho_{1}$ the density of water $\left(\mathrm{kg} / \mathrm{m}^{3}\right), \beta$ the vapour surface coefficient $(\mathrm{s} / \mathrm{m}), \mathrm{p}_{\mathrm{vsat}}$ the vapour saturation pressure $(\mathrm{Pa})$ dependent on temperature $\mathrm{T}, \phi_{\mathrm{e}}$ the relative humidity of the environment and $\mathrm{S}(\mathrm{t})\left(\mathrm{m}^{2}\right)$ the surface of the cap. The volume $\mathrm{V}(\mathrm{t})$ of the cap in Eq. 2 is given by:

$V(t)=\frac{\pi}{24} d^{\prime}(t)^{3} f_{V}(\theta)$

where $f_{V}(\theta)$ is a function of the contact angle:

$$
f_{V}(\theta)=\frac{(1-\cos \theta)^{2}(2+\cos \theta)}{(\sin \theta)^{3}}
$$

The surface $\mathrm{S}(\mathrm{t})$ of the cap in Eq. 2 is given by:

$$
S(t)=\frac{\pi}{2} d^{\prime}(t)^{2} f_{S}(\theta)
$$

where

$$
f_{S}(\theta)=\frac{1}{1+\cos \theta}
$$

Combining Eqs. 2 and 3, the diameter d'(t) can be written as: 
$d^{\prime}(t)=\sqrt[3]{d_{0}^{\prime 3}-\frac{\Delta V(t)}{\frac{\pi}{24} f_{V}(\theta)}}$

The following strategy is used to calculate the time variation of the volume $V(t)$ of the cap. Knowing the diameter d'(t) at time step t, Eq. (5) is used to calculate the surface $\mathrm{S}(\mathrm{t})$. Then, the volume variation $\Delta \mathrm{V}$ at a new time $t+\Delta t$ is calculated using Eq. (2). From Eq. (7) the new diameter $d^{\prime}(t+\Delta t)$ is then determined. A crucial but also very complex boundary condition for evaporation is represented by the vapour transfer coefficient $\beta$. The vapour transfer coefficient is a function of the local mean wind speed and local turbulence, which in turn are pronounced functions of the building geometry, position at the building facade, facade roughness, reference wind speed and reference wind direction (e.g. [32-36]). To the best of our knowledge, there are no correlations or functions for $\beta$ that take into account all of these factors. For windward facades, which are those exposed to WDR, Janssen et al. [36] provided an equation for $\beta(\mathrm{s} / \mathrm{m})$ based on Sharples [32] and the Lewis analogy that takes into account the effect of a reference wind speed $U_{10}(\mathrm{~m} / \mathrm{s})$ in open field at $10 \mathrm{~m}$ height and is applicable for smooth facades:

$\beta=7.7 \times 10^{-9}\left(3.06 U_{10}+5.44\right)$

However, this equation still does not take into account variations in building geometry, position at the building facade, facade roughness and reference wind direction. Earlier studies on convective heat transfer coefficients (which - given certain assumptions - can be related to convective moisture transfer coefficients by the Lewis analogy) demonstrated that differences in building geometry and differences in positions at the building facade can cause variations in values at windward facades up to a factor 4 [35], while differences in surface roughness (smooth versus rough plaster) can cause differences up to a factor 2.17 ([33,34], see also Table 1).

As an example of the droplet evaporation model, Figure 11 shows the variation of the mass $M$ with $M(t)=$ $\mathrm{V}(\mathrm{t}) \cdot \rho_{1}$ for a rain droplet with contact angle $\theta=90^{\circ}$, initial base diameter $\mathrm{d}_{0}$ ' $=1 \mathrm{~mm}$, for a range of $\beta$ values: $40 \times 10^{-9} \mathrm{~s} / \mathrm{m}$ to $400 \times 10^{-9} \mathrm{~s} / \mathrm{m}$, in intervals of $40 \times 10^{-9} \mathrm{~s} / \mathrm{m}$. According to Eq. (8), these values correspond to reference wind speed $U_{10}=1.6 \mathrm{~m} / \mathrm{s}$ to $15.2 \mathrm{~m} / \mathrm{s}$, in intervals of $1.7 \mathrm{~m} / \mathrm{s}$, all of which are realistic values for wind speed in the lowest part of the atmospheric boundary layer. In addition, $\mathrm{T}=10{ }^{\circ} \mathrm{C}$ (yielding $\mathrm{p}_{\mathrm{vsat}}=1212 \mathrm{~Pa}$ ) and $\phi=80 \%$. This drying model has been combined with the drop distribution and drop runoff model to include the effects of evaporation on the resulting runoff amounts, as will be shown for a case study in the next section.

\section{Case study}

\subsection{Building model}

The case study focuses on a two-storey building with gable roof and with a small detached garage (Fig. 12). The building itself is $10.9 \mathrm{~m}$ long and $8.15 \mathrm{~m}$ wide. Its total height is $8.5 \mathrm{~m}$. The depth of the sloped roof overhangs is $30 \mathrm{~cm}$. The height of the garage is $3 \mathrm{~m}$. The orientation of the longitudinal facade deviates $15^{\circ}$ from the exact south-west orientation. This south-west facing facade is $3 \mathrm{~m}$ high and contains two windows A2 and A3 of different size. Both windows are recessed $0.1 \mathrm{~m}$ into the wall. Window A2 is the focus of the present case study.

\subsection{Computational settings and parameters}

The dimensions of the computational domain are based on the best practice guidelines by Tominaga et al. [37] and Franke et al. [38]. A computational grid with about $10^{6}$ tetrahedral control volumes is constructed. The inlet profile of mean wind speed is described by the logarithmic law (Eq. 9), where $u^{*}$ is the friction velocity, $\kappa$ the von Karman constant equal to $0.42, \mathrm{z}_{0}$ the aerodynamic roughness length $(0.03 \mathrm{~m})$ and $\mathrm{z}$ the height coordinate:

$\mathrm{U}(\mathrm{z})=\frac{\mathrm{u}^{*}}{\kappa} \ln \left(\frac{\mathrm{z}+\mathrm{z}_{0}}{\mathrm{z}_{0}}\right)$

The profiles of turbulent kinetic energy $\mathrm{k}$ and turbulence dissipation rate $\varepsilon$ are those by Richards and Hoxey [39]: 


$$
\begin{aligned}
& \mathrm{k}=\frac{\mathrm{u}^{*_{2}}}{\sqrt{C_{\mu}}} \\
& \varepsilon(\mathrm{z})=\frac{\mathrm{u}^{{ }_{3}}}{\mathrm{\kappa}\left(\mathrm{z}+\mathrm{z}_{0}\right)}
\end{aligned}
$$

where $\mathrm{C}_{\mu}$ is an empirical constant taken equal to 0.09 . On the ground surface, a rough-wall boundary condition is imposed to include the effects of the upstream roughness on the development of the flow. The standard wall functions by Launder and Spalding [40] with roughness modification by Cebeci and Bradshaw [41] are used. The roughness parameters, i.e. the equivalent sand-grain roughness height $\left(\mathrm{k}_{\mathrm{s}}\right)$ and the roughness constant $\left(\mathrm{C}_{\mathrm{s}}\right)$, are determined from the aerodynamic roughness length $\mathrm{z}_{0}$ according to the relation derived by Blocken et al. $[42,43]$. For Fluent 6.3, this relationship is:

$$
\mathrm{k}_{\mathrm{S}}=\frac{9.793 z_{0}}{\mathrm{C}_{\mathrm{s}}}
$$

Note however that $\mathrm{k}_{\mathrm{s}}$ should be smaller than the height of the centroid of the wall-adjacent cells from the wall. The selected values are: $\mathrm{k}_{\mathrm{s}}=0.147 \mathrm{~m}_{\mathrm{s}}$ and $\mathrm{C}_{\mathrm{s}}=2$. At the top and lateral sides of the domain, symmetry boundary conditions are applied to impose zero normal velocity and zero normal gradients of all variables. At the outlet of the domain, a zero static pressure condition is prescribed. Standard wall functions with $\mathrm{k}_{\mathrm{s}}=0$ (smooth walls) are applied for all the building surfaces.

The commercial code Fluent 6.3 [44] was used to solve the 3D steady RANS equations with the realizable k$\varepsilon$ model [27]. The SIMPLE algorithm was used for pressure-velocity coupling. Second-order discretisation schemes were used for the viscous and convection terms of the governing equations. Second-order interpolation was used for pressure. Convergence was obtained when the scaled residuals levelled off and reached a minimum of $10^{-6}$ for $\mathrm{x}-, \mathrm{y}-$ and $\mathrm{z}$-velocity, $10^{-5}$ for $\mathrm{k}$ and $10^{-4}$ for $\varepsilon$ and continuity.

\subsection{Wind-flow pattern and raindrop trajectories}

In Flanders, Belgium, the prevailing wind direction is south-west. Therefore, this wind direction was chosen for this study. Some results of the CFD analysis (mean velocity vectors in a horizontal plane at a height of $1.75 \mathrm{~m}$ ) are given in Figure 13. Note the influence of the garage on the flow pattern around the two-storey building. For the WDR analysis, the reference facade $(10.9 \times 3 \mathrm{~m})$ was divided into three main rectangular areas (Fig. 12). Area A1 is the facade without windows, area A2 is a window $(0.9 \times 1.4 \mathrm{~m})$ with a sill at $1 \mathrm{~m}$ above the ground and area $\mathrm{A} 3$ is a larger window $(1.8 \times 2.4 \mathrm{~m})$. As mentioned before, in this paper, the focus is mainly on the small window area $\mathrm{A} 2$.

Raindrop trajectories for wind-flow patterns with different reference wind speed $\left(\mathrm{U}_{10}=1,2,3,4,5,6,8,10\right.$ $\mathrm{m} / \mathrm{s}$ ) were obtained for 17 different raindrop sizes, with diameters $0.3,0.4,0.5,0.6,0.7,0.8,0.9,1.0,1.2,1.4$, $1.6,1.8,2.0,3.0,4.0,5.0,6.0 \mathrm{~mm}$. The raindrops were equidistantly injected from a horizontal plane at a height of $100 \mathrm{~m}$. Figure 14 shows examples of raindrop trajectories arriving at or near window A2, illustrating the influence of wind speed and raindrop size. In general, for small raindrops and high wind speeds, the trajectories are more inclined and more distorted near the building. For larger drops and lower wind speeds, the trajectories are more rectilinear (larger inertia). The figure also shows the shading effect of the roof overhang and the effect of the recession of the window in the facade.

\subsection{Specific catch ratio}

Based on the configuration of the raindrop trajectories, specific catch ratios $\eta_{\mathrm{d}}$ were obtained for the entire facade. They are illustrated in Figure 15 for a few combinations of wind speed and raindrop size. The specific catch ratios over the facade are clearly asymmetrical. This is due to the presence of the garage and the wind directions, which is not exactly perpendicular to the facade (the deviation angle of the wind direction from the normal to the facade is $15^{\circ}$ ). The garage acts as a wind and rain obstacle, as noticed at the left side of the facade for the smaller raindrop sizes. The parts of the facade that are sheltered from rain by the roof overhang, the window recession or the garage are coloured black. It was found that for wind speed $U_{10} \leq 2 \mathrm{~m} / \mathrm{s}$, the whole facade, i.e. all areas (A1, A2, A3), were/are sheltered from rain. In general, the smaller window A2 is more protected from rain than window $\mathrm{A} 3$. 


\subsection{Rain events, runoff and evaporation}

The droplet-behaviour model is used to calculate the amount of rainwater runoff from the small window A2 for two different rain events, taking into account evaporation during and between the different rain periods in these events. The two rain events, a cumuliform rain event and a stratiform rain event, are chosen because of their different characteristics. The terminology "cumuliform-stratiform" stems from the type of clouds generating the rain. Cumuliform clouds or heap clouds (Fig. 16a) develop in an unstable atmosphere as a result of fast and local rising air currents. The type of rainfall from these clouds is referred to as showers (Fig. 16b). Showers usually start and stop suddenly and are generally of short duration. Stratiform clouds or layer clouds (Fig. 16c) develop in a stable atmosphere as a result of widespread cooling and by condensation processes that are slow but persistent. The precipitation from these clouds starts and stops slowly, is quite steady (although it can exhibit breaks), often lasts for many hours and is generally of light to moderate intensity $\left(R_{h}<7.6 \mathrm{~mm} / \mathrm{h}\right)$ (Fig. 16d). The window area was partitioned into 50400 square surfaces of about $5 \times 5 \mathrm{~mm}^{2}$. The two rain events were partitioned into 10-minute time steps and for each time step, the horizontal rainfall amount was broken up into a large number of discrete rain drops. Based on visual observations during experiments, the contact angle $\theta$ for drops at the glass surface was set to $90^{\circ}$, meaning that each surface-pendent drop is half a sphere, as in Figure 9. The environmental conditions are the following: $\beta=200 \times 10^{-9} \mathrm{~s}, \mathrm{~T}=10^{\circ} \mathrm{C}$ and $\phi_{\mathrm{e}}=60 \%$ in dry periods and $90 \%$ during rain, which are typical values for Flanders, as measured at the VLIET test site during rain events. Especially the constant value for $\beta$ is a significant simplification, made in absence of better knowledge of this parameter as a complex function of building geometry, position at the building facade, facade roughness, reference wind speed and reference wind direction. Note that the value of $200 \times 10^{-9} \mathrm{~s} / \mathrm{m}$ is chosen as the combination of Eq. (8) for $\mathrm{U}_{10}=4 \mathrm{~m} / \mathrm{s}$ (close to average wind speed in the rain events) and a facade of brick, yielding a roughness factor of about 1.67 for convective heat/moisture transfer (see Table 1, [33,34]).

Figures $16 \mathrm{e}$ and $\mathrm{f}$ show the cumulative amount of runoff (in litre per meter of horizontal length) at the bottom part of window A2 during each rain event. Calculations have been made without evaporation and with evaporation, at $\mathrm{T}=10^{\circ} \mathrm{C}$ and for the cumuliform rain event also at $\mathrm{T}=20^{\circ} \mathrm{C}$. For the cumuliform rain event that is characterised by discrete rain showers intermitted by quite long dry periods, evaporation appears to be quite important: it decreases the total amount of runoff by $26 \%$. The reason is that a large number of raindrops stay adhered to the surface, and in the many dry periods (see Fig. 16b), they have the opportunity to evaporate. The effect of temperature during evaporation is present, but not very pronounced. For the stratiform rain event that is characterised by an almost continuous rainfall with very few interruptions, the relative humidity remains high throughout the rain event and the effect of evaporation is small. This is also caused by the absence of dry interruptions in the rain event, and therefore the lesser opportunity for evaporation of rainwater that is adhered to the surface. In this case, evaporation only decreases the total amount of runoff by $4 \%$.

\section{Discussion}

Validation is essential to be able to apply models such as those presented in this paper with confidence. The CFD model used was validated for a low-rise VLIET test building of complex geometry and for a range of different rain events $[25,26]$. More recently, the model was also successfully validated for another low-rise building [45], for two different high-rise buildings [46,47] and for an array of low-rise buildings [14]. These studies provide confidence for the extrapolated use of the CFD model for different building configurations and different rain events. Nevertheless, additional validation efforts will required in the future.

The drop-behaviour model is a semi-empirical model, which means that it has a theoretical basis but that a number of its parameters have been obtained by means of experimental data. Note that the calculations presented here were performed based on experimental data obtained on PMMA and glass surfaces. Based on these data, a contact angle of $90^{\circ}$ was taken in the model. However, a wide range of glass-type surfaces exist, with coatings that exhibit behaviour ranging from superhydrophylic to superhydrophobic. Further research is needed for different types of glass surfaces. Another assumption made in the present model is that rain is present at the surface as individual drops, and not as a water film. This assumption is justified for hydrophobic surfaces and can be justified for regular hydrophilic surfaces. At superhydrophilic surfaces however, water films will occur at the surface rather than individual drops. In that case, modifications to the drop-behaviour model are needed.

The relevance of this research is indicated for example by the problem of "self-cleaning glass". Self-cleaning glass surfaces are increasingly being used in the construction industry to limit maintenance costs. This type of glass is treated by a special superhydrophilic or superhydrophobic coating to promote raindrop runoff, which would in turn rinse the surface during WDR and remove dust particles. The models presented in this study are used by the authors to analyse the performance of "self-cleaning" glazed surfaces mounted on real buildings, focusing on the amount of WDR received, the wetting-drying cycles (causing dirt stains), runoff, etc. 


\section{Conclusions}

Two models for the study of wind-driven rain (WDR) impact, runoff and drying of an impervious, smooth, vertical surface have been presented. The first model is a CFD model that calculates the amount of WDR on different parts of the facade. It provides specific catch ratio charts that are used as input into the second model. The second model is a semi-empirical drop-behaviour model that models the coagulation, adhesion, runoff and evaporation of individual droplets on a (vertical) surface.

Both models have been applied for a small window in a typical small two-storey house under meteorological conditions (see Fig. 16) that are typical for western European countries. It is shown that by far not all winddriven rain water that falls onto a window or onto another impervious part of the facade runs off. A significant amount of rainwater, that is at first adhered to the surface, can evaporate and will leave dirt stains behind. These models can be used to provide the knowledge about WDR impact, runoff and evaporation that is needed for the performance assessment of self-cleaning glass surfaces.

\section{Acknowledgements}

Former postdoctoral fellow Monika Rychtarikova assisted with the construction of the computational grid. This assistance is gratefully acknowledged. The authors are also very grateful to the editor and the two anonymous reviewers for the very valuable comments that have substantially improved this paper.

\section{References}

[1] Eldridge HJ. 1976 Common defects in buildings, HMSO, 486 p.

[2] Blocken B, Carmeliet J. 2004. A review on wind-driven rain research in building science. Journal of Wind Engineering and Industrial Aerodynamics: 92(13): 1079-1130.

[3] Euvananont C, Junin C, Inpor K, Limthongkul P, Thanachayanont C. 2008. $\mathrm{TiO}_{2}$ optical coating layers for self-cleaning applications. Ceramics International 34(4): 1067-1071.

[4] Kaegi R, Ulrich A, Sinnet B, Vonbank R, Wichser A, Zuleeg S, Simmler H, Brunner S, Vonmont H, Burkhardt M, Boller M. 2008. Synthetic $\mathrm{TiO}_{2}$ nanoparticle emission from exterior facades into the aquatic environment. Environmental Pollution 156(2): 233-239.

[5] Wittmer IK, Scheidegger R, Stamm C, Gujer W, Bader HP. 2011. Modelling biocide leaching from facades. Water Research 45(11): 3453-3460.

[6] Wangler TM, Zuleeg S, Vonbank R, Bester K, Boller M, Carmeliet J, Burkhardt M. 2012. Laboratory scale studies of biocide leaching from facade coatings. Building and Environment 54: 168-173.

[7] Blocken B, Carmeliet J. 2010. Overview of three state-of-the-art wind-driven rain assessment models and comparison based on model theory. Building and Environment 45(3): 691-703.

[8] Blocken B, Stathopoulos T, Carmeliet J, Hensen JLM. 2011. Application of CFD in building performance simulation for the outdoor environment: an overview. Journal of Building Performance Simulation 4(2): 157-184.

[9] Moonen P, Defraeye T, Dorer V, Blocken B, Carmeliet J. 2012. Urban physics: effect of the microclimate on comfort, health and energy demand. Frontiers of Architectural Research 1(3): 197-228.

[10] Blocken B. 2014. 50 years of Computational Wind Engineering: Past, present and future. Journal of Wind Engineering and Industrial Aerodynamics 129: 69-102.

[11] Erkal A, D'Ayala D, Sequeira L. 2012. Assessment of wind-driven rain impact, related surface erosion and surface strength reduction of historic building materials. Building and Environment 57: 336-348.

[12] Coutu S, Wyrsch V, Rossi L, Emery P, Golay F, Carneiro C. 2013. Modelling wind-driven rain on buildings in urbanized area using 3-D GIS and LiDAR datasets. Building and Environment 59: 528-535.

[13] Pérez-Bella JM, Domínguez-Hernández J, Rodríguez-Soria B, del Coz-Díaz JJ, Cano-Suñén E. 2013. Combined use of wind-driven rain and wind pressure to define water penetration risk into building façades: The Spanish case. Building and Environment 64: 46-56.

[14] Kubilay A, Derome D, Blocken B, Carmeliet J. 2014. Numerical simulations of wind-driven rain on an array of low-rise cubic buildings and validation by field measurements. Building and Environment 81: 283-295.

[15] Künzel HM, Kiessl K. 1997.Calculation of heat and moisture transfer in exposed building components. International Journal of Heat and Mass Transfer 40(1): 159-167.

[16] Blocken B, Roels S, Carmeliet J. A combined CFD-HAM approach for wind-driven rain on building facades. Journal of Wind Engineering and Industrial Aerodynamics 2007; 95(7): 585-607.

[17] Abuku M, Janssen H, Poesen J, Roels S. 2009. Impact, absorption and evaporation of raindrops on building facades. Building and Environment 44(1): 113-124. 
[18] Straube JF. Moisture control and enclosure wall systems, Ph.D. thesis, Civil Engineering, University of Waterloo, Ontario, Canada, 1998, 318 p.

[19] Beijer O. 1977. Concrete walls and weathering, RILEM/ASTM/CIB Symposium on Evaluation of the Performance of External Vertical Surfaces of Buildings, vol. 1, Otaniemi, Espoo, Finland, August 28-31 and September 1-2, pp. 67-76.

[20] Hall C, Kalimeris AN. 1982. Water movement in porous building materials - V. Absorption and shedding of rain by building surfaces. Building and Environment 17(4): 257-262.

[21] Blocken B, Carmeliet J. 2012. A simplified numerical model for rainwater runoff on building facades: possibilities and limitations. Building and Environment 53: 59-73.

[22] Van den Brande T, Blocken B, Roels S. 2013. Rain water runoff from porous building facades: implementation and application of a first-order runoff model coupled to a HAM model. Building and Environment 64: 177-186.

[23] Blocken B, Derome D, Carmeliet J. 2013. Rainwater runoff from building facades: a review. Building and Environment 60: 339-361.

[24] Choi, E.C.C., 1993. Simulation of wind-driven rain around a building. Journal of Wind Engineering and Industrial Aerodynamics 46\&47, 721-729.

[25] Blocken B, Carmeliet J. 2002. Spatial and temporal distribution of driving rain on a low-rise building. Wind and Structures 5(5): 441-462.

[26] Blocken B, Carmeliet J. 2007. Validation of CFD simulations of wind-driven rain on a low-rise building. Building and Environment 42(7): 2530-2548.

[27] Shih, T.H., Liou, W.W., Shabbir, A., Yang, Z., Zhu, J. 1995. A new k- $\varepsilon$ eddy viscosity model for high Reynolds number turbulent flows. Computers \& Fluids; 24 : 227-238.

[28] Blocken B, Carmeliet J. 2006. On the accuracy of wind-driven rain measurements on buildings. Building and Environment 41(12): 1798-1810.

[29] Blocken B, Carmeliet J. 2005. High-resolution wind-driven-rain measurements on a low-rise building experimental data for model development and model validation. Journal of Wind Engineering and Industrial Aerodynamics 93(12): 905-928.

[30] Best AC. 1950. The size distribution of raindrops. Quarterly Journal of the Royal Meteorological Society 76: 16-36.

[31] Blocken B, Carmeliet J. 2006. The influence of the wind-blocking effect by a building on its wind-driven rain exposure. Journal of Wind Engineering and Industrial Aerodynamics 94(2): 101-127.

[32] Sharples, S. 1984. Full scale measurements of convective energy losses from exterior building surfaces. Build. Environ 19: 31-39.

[33] Walton, G.N. 1981. Passive solar extension of the building loads analysis and system thermodynamics (BLAST) program, United States Army Construction Engineering Research Laboratory, Champaign, IL, 1981.

[34] ASHRAE, 1981. ASHRAE Handbook of Fundamentals. Atlanta, GA, USA.

[35] Blocken, B., Defraeye, T., Derome, D., Carmeliet, J., 2009. High-resolution CFD simulations for forced convective heat transfer coefficients at the facade of a low-rise building. Build. Environ. 44: 2396-2412.

[36] Janssen H, Blocken B, Carmeliet J. Conservative modelling of the moisture and heat transfer in building components under atmospheric excitation. International Journal of Heat and Mass Transfer 2007; 50(5-6): $1128-1140$.

[37] Tominaga, Y., Mochida, A., Yoshie, R., Kataoka, H., Nozu, T., Yoshikawa, M., Shirasawa, T., 2008. AIJ guidelines for practical applications of CFD to pedestrian wind environment around buildings. J. Wind Eng. Ind. Aerodyn. 96(10-11), 1749-1761.

[38] Franke, J., Hellsten, A., Schlünzen, H., Carissimo, B., 2007. Best practice guideline for the CFD simulation of flows in the urban environment.

[39] Richards PJ, Hoxey RP. Appropriate boundary conditions for computational wind engineering models using the k- $€$ turbulence model. J Wind Eng Ind Aerodyn. 1993;46-47:145-153.

[40] Launder, B.E., Spalding, D.B., 1974. The numerical computation of turbulent flows. Comput. Method Appl. M 3, 269-289.

[41] Cebeci, T., Bradshaw, P., 1977. Momentum transfer in boundary layers. Hemisphere Publishing Corp, New York.

[42] Blocken, B., Stathopoulos, T., Carmeliet, J., 2007. CFD simulation of the atmospheric boundary layer: wall function problems. Atmos. Environ. 41(2), 238-252.

[43] Blocken, B., Carmeliet, J., Stathopoulos, T., 2007. CFD evaluation of the wind speed conditions in passages between buildings - effect of wall-function roughness modifications on the atmospheric boundary layer flow. J. Wind Eng. Ind. Aerodyn. 95(9-11), 941-962.

[44] Fluent Inc., 2006. Fluent 6.3 User's Guide. Fluent Inc., Lebanon. 
[45] Abuku M, Blocken B, Nore K, Thue JV, Carmeliet J, Roels S. 2009. On the validity of numerical winddriven rain simulation on a rectangular low-rise building under various oblique winds. Building and Environment 44(3): 621-632.

[46] Tang W, Davidson CI. Erosion of limestone building surfaces caused by wind-driven rain. 2. Numerical modelling. Atmospheric Environment 2004; 38(33): 5601-5609.

[47] Briggen PM, Blocken B, Schellen HL. 2009. Wind-driven rain on the facade of a monumental tower: numerical simulation, full-scale validation and sensitivity analysis. Building and Environment 44(8): 1675-1690.

Table 1. Roughness multiplier for convective heat (and moisture) transfer [33,34].

\begin{tabular}{lll}
\hline Roughness index & $R_{f}$ & Example material \\
\hline Very rough & 2.17 & Stucco \\
Rough & 1.67 & Brick \\
Medium rough & 1.52 & Concrete \\
Medium smooth & 1.13 & Clear pine \\
Smooth & 1.11 & Smooth plaster \\
Very smooth & 1.00 & Glass \\
\hline
\end{tabular}




\section{FIGURES}

(a)

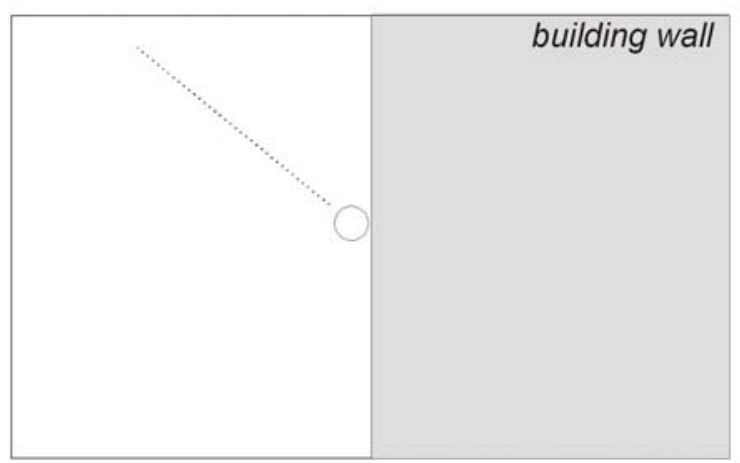

(b)

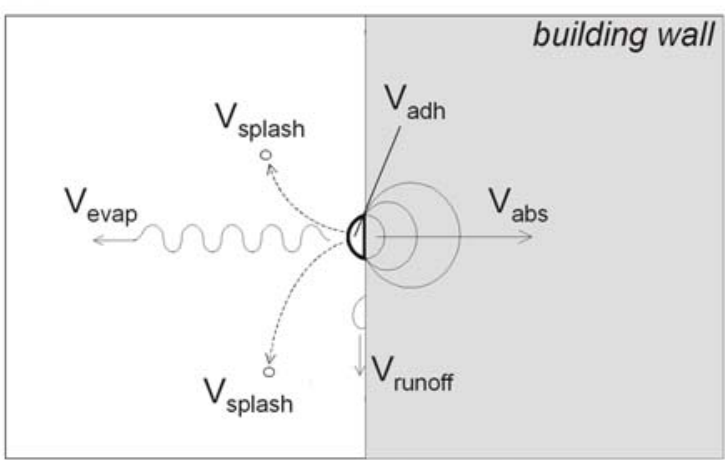

Figure 1: Schematic representation of the two parts in wind-driven rain research: (a) assessment of the impinging wind-driven rain intensity (before rain impact) and (b) assessment of the response of the wall (at and after rain impact).

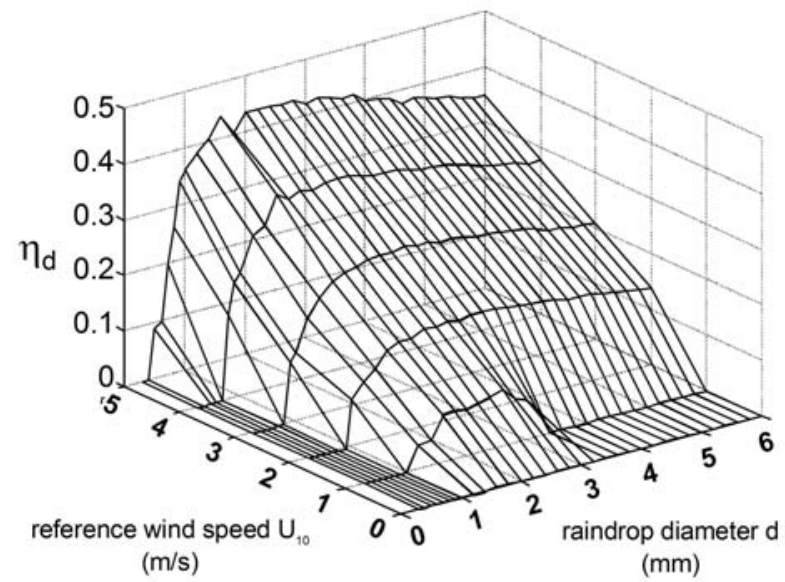

Figure 2. Example of a specific catch ratio chart illustrating $\eta_{d}$ as a function of the reference wind speed $U_{10}$ $(\mathrm{m} / \mathrm{s})$ and the raindrop diameter $\mathrm{d}(\mathrm{mm})$ for a given wind direction and a given facade position.

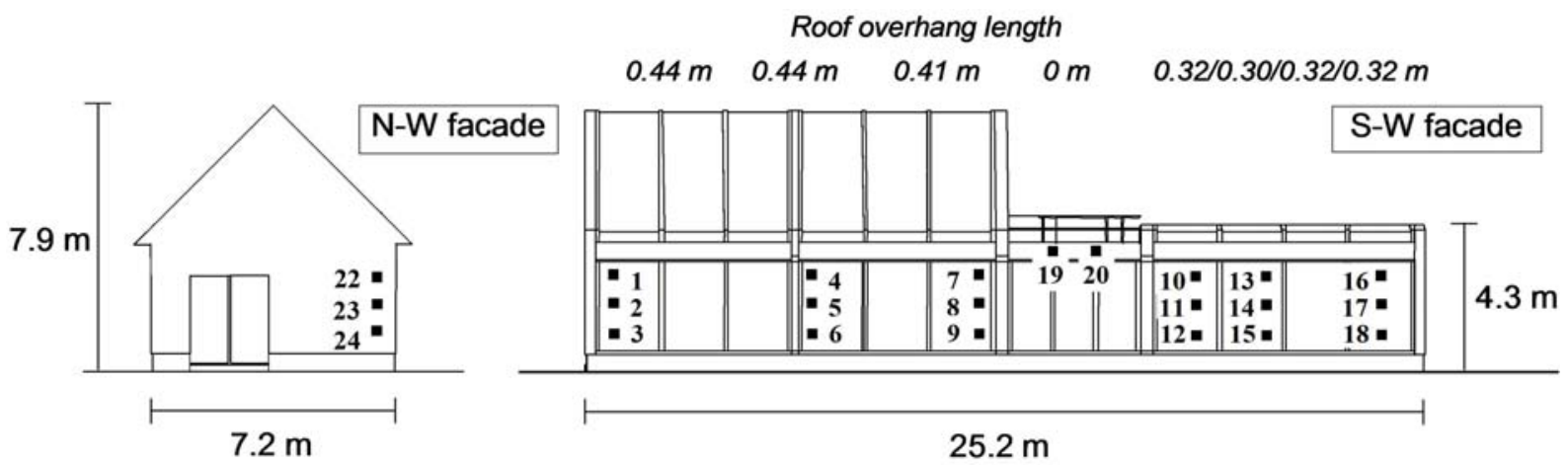

Figure 3. VLIET test building. North-west and south-west facade. The building dimensions, including roof overhang length, and the positions and numbers of the wind-driven rain gauges (indicated by black squares) are indicated. 


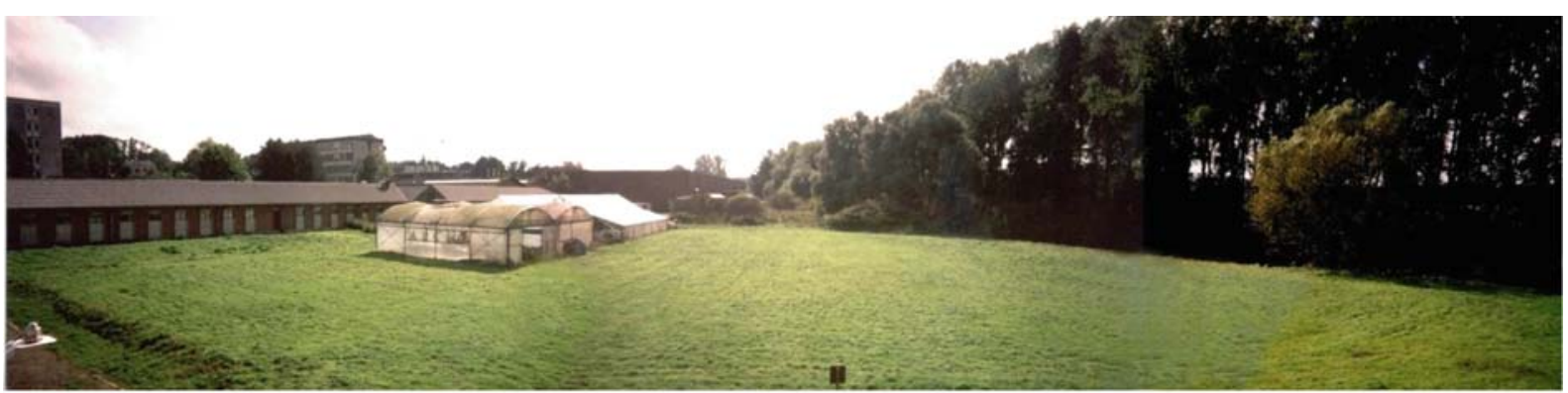

Figure 4. View at the site south-west of the VLIET building (Photograph taken with the back against the southwest facade).

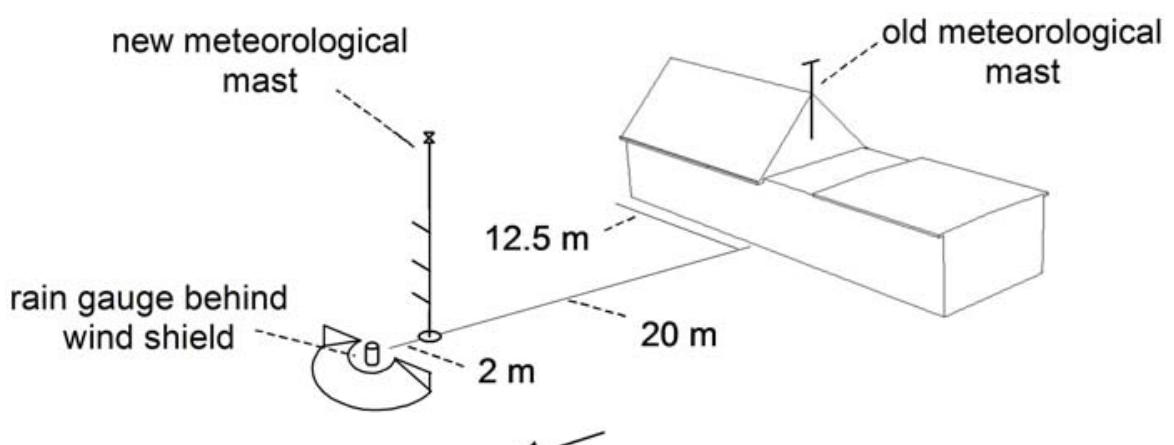

sw

Figure 5. Location of the (new) meteorological station (mast and horizontal rain gauge) in front of the south-west facade. 
(a)

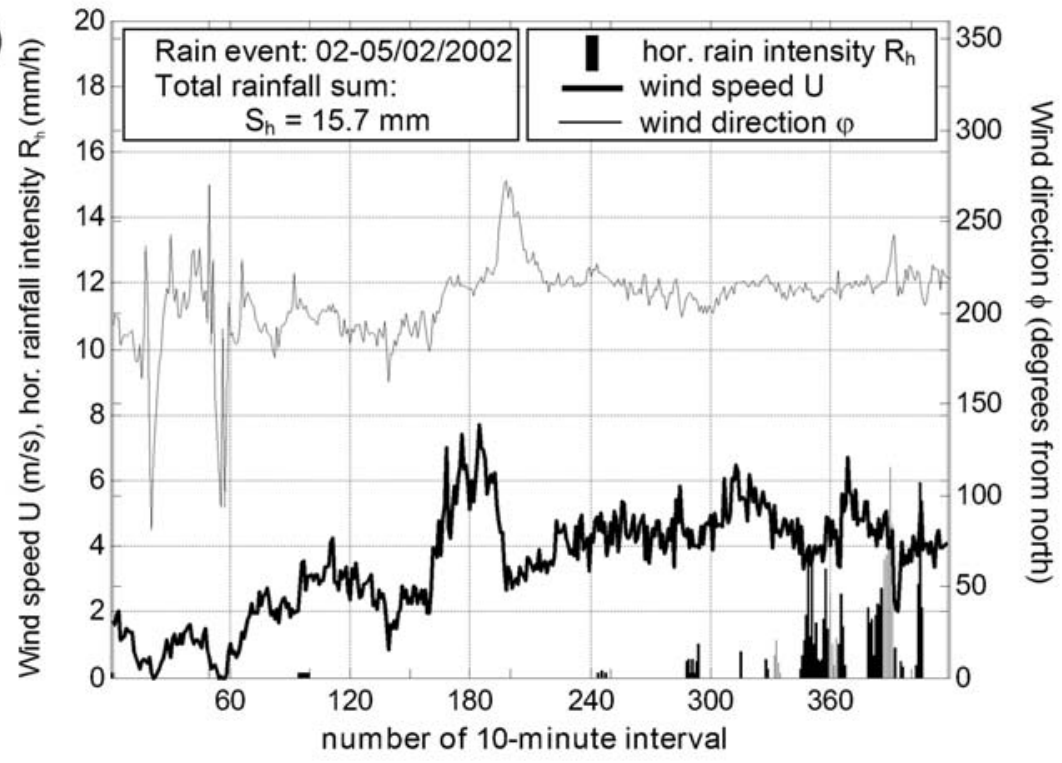

(b)

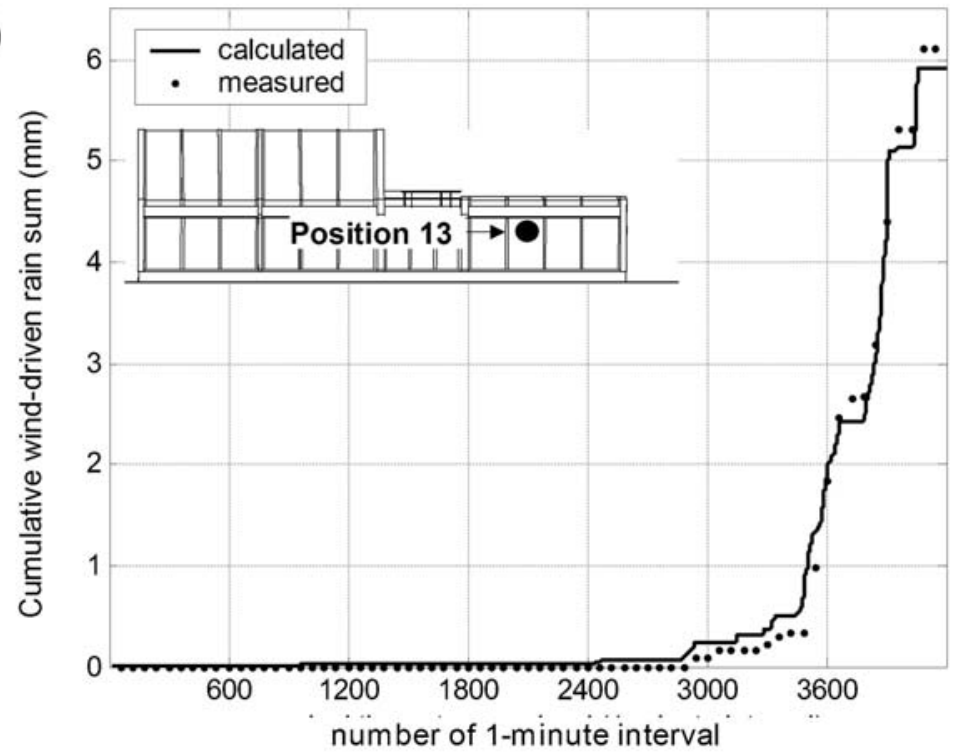

Figure 6. (a) Meteorological data (reference wind speed, wind direction, horizontal rainfall intensity) measured during the rain event $(02-05 / 02 / 2002)$. Total horizontal rainfall amount $S_{h}=15.7 \mathrm{~mm}$. (b) Temporal distribution of the experimentally and numerically determined cumulative wind-driven rain amount at position 13 of the south-west facade. 

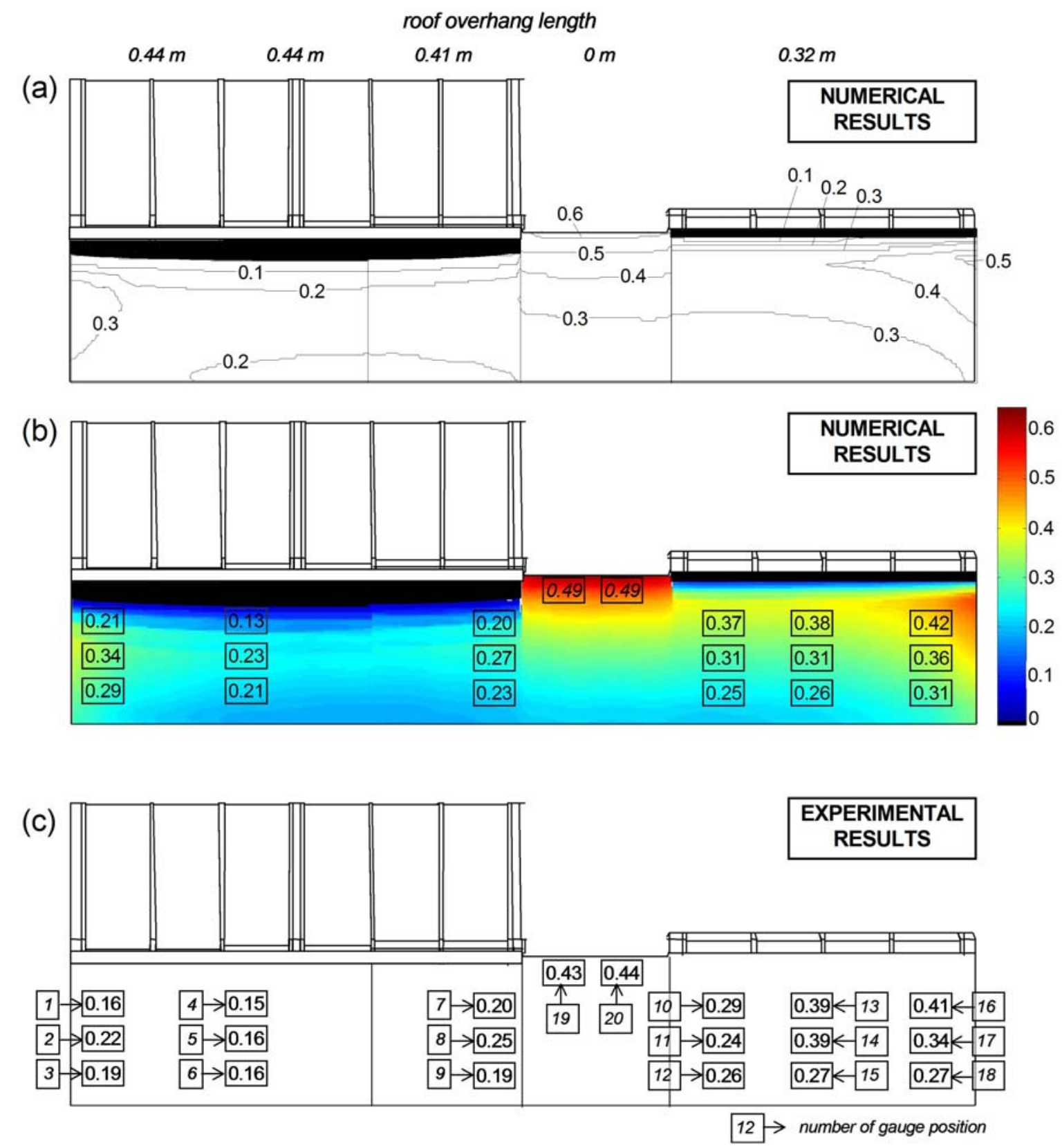

Figure 7. Spatial distribution of the ratio $\mathrm{S}_{\mathrm{wdr}} / \mathrm{S}_{\mathrm{h}}$ (total wind-driven rain amount to total horizontal rainfall amount) for the rain event (02-05/02/2002) (rain event is illustrated in Fig. 6a). The total horizontal rainfall amount $\mathrm{S}_{\mathrm{h}}=15.7 \mathrm{~mm}$. (a-b) Numerical results. In Fig. 7b, the calculated ratios at the location of the wind-driven rain gauges are additionally indicated. (c) Experimental results. 


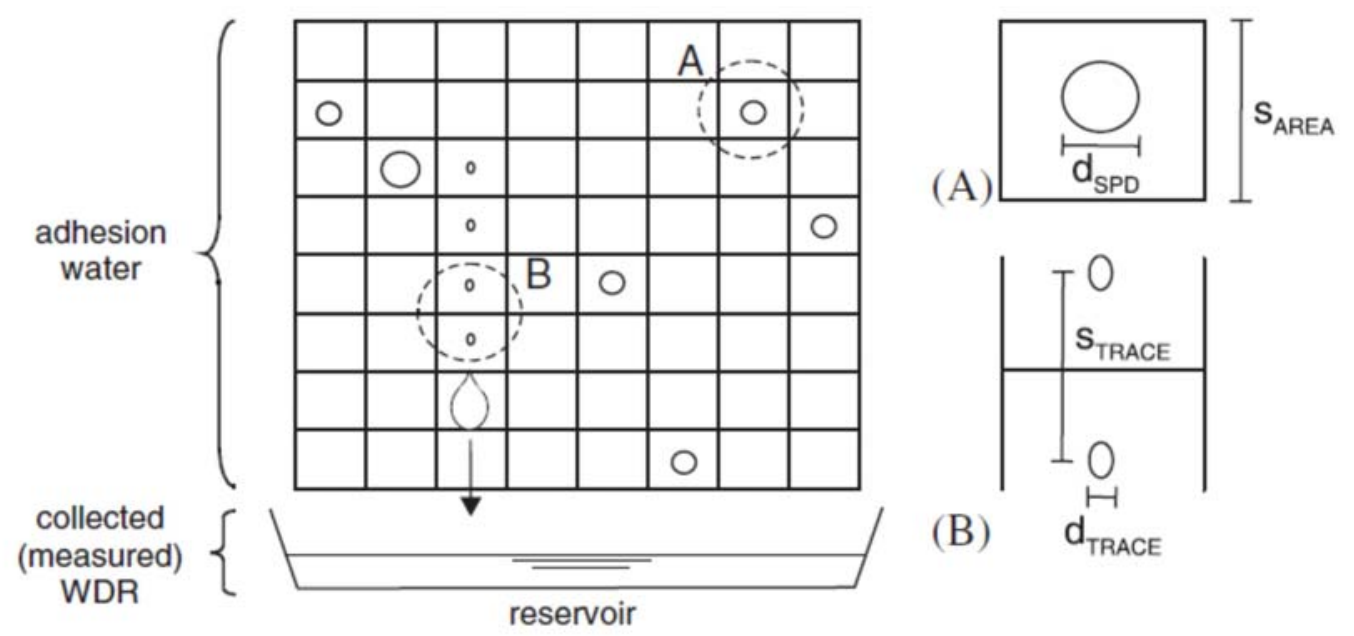

Figure 8. Graphical representation of model for drop behaviour: rectangular grid on a vertical surface and indication of raindrop adhesion and runoff.

a

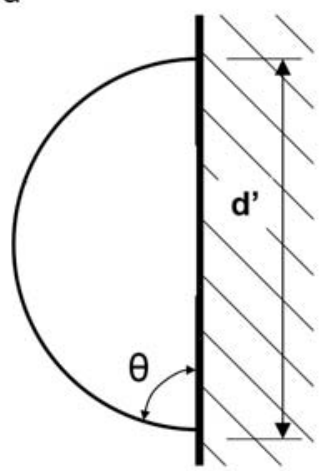

b

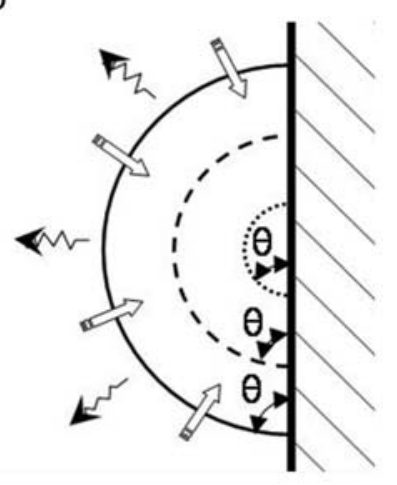

Figure 9. (a) A raindrop with diameter d arriving at a vertical surface spreads out to form a surface pendent drop (SPD) with diameter $\mathrm{d}^{\prime}=\mathrm{d}_{\mathrm{SPD}}$. (b) Drying and shrinking of a raindrop on a vertical surface while the contact angle $\theta$ remains constant.

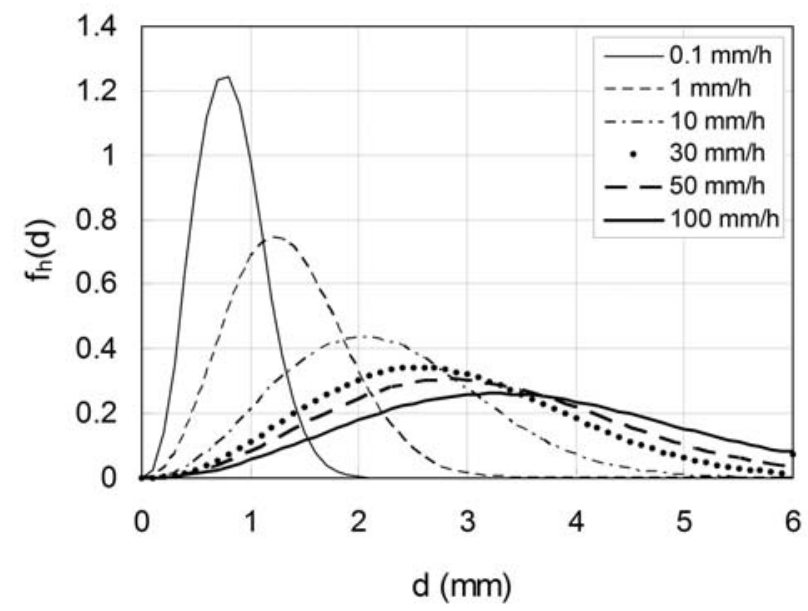

Figure 10. Probability-density function $\mathrm{f}_{\mathrm{h}}(\mathrm{d})$ of raindrop size. The function refers to rainfall through a horizontal plane with the reference rainfall intensity $R_{h}$ as a parameter - calculated from the raindrop-size distribution in the air according to Best [30]. 


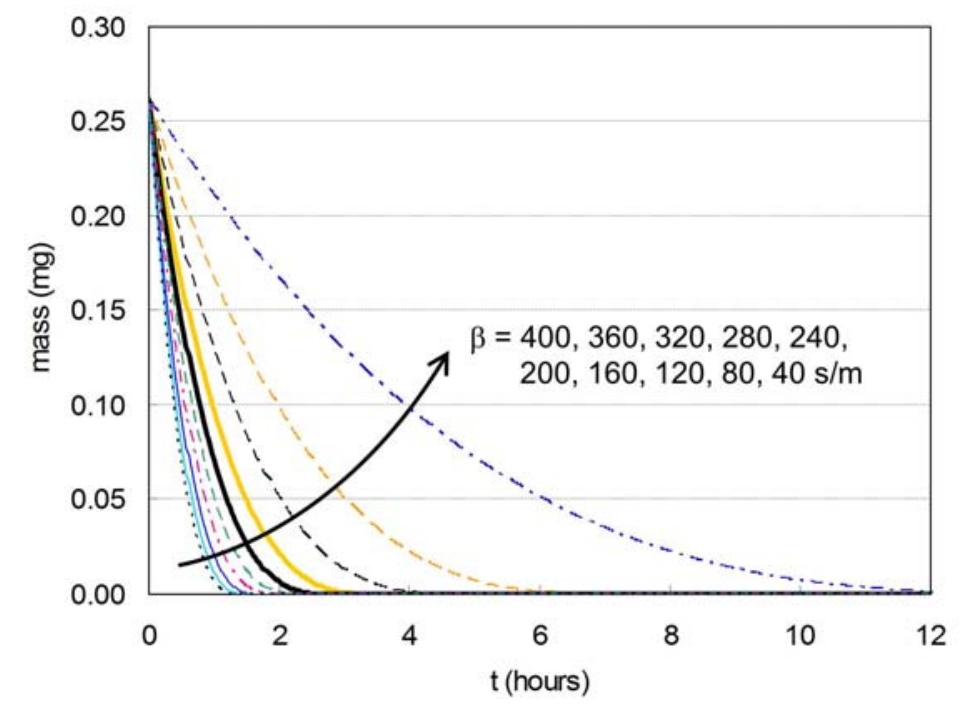

Figure 11. Drying time of a droplet on a vertical surface. Initial diameter: $\mathrm{d}_{0}{ }^{\prime}=1 \mathrm{~mm}$, vapour transfer coefficient $\beta=40 \times 10^{-9} \mathrm{~s} / \mathrm{m}$ to $400 \times 10^{-9} \mathrm{~s} / \mathrm{m}$, in intervals of $40 \times 10^{-9} \mathrm{~s} / \mathrm{m} ., \mathrm{T}=10^{\circ} \mathrm{C}$ and $\phi_{\mathrm{e}}=80 \%$.

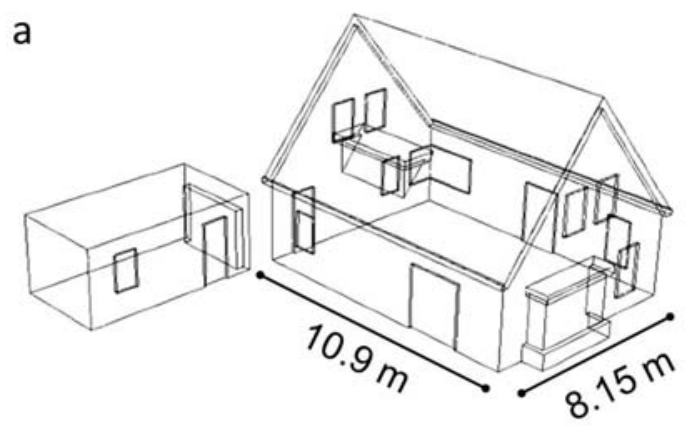

C
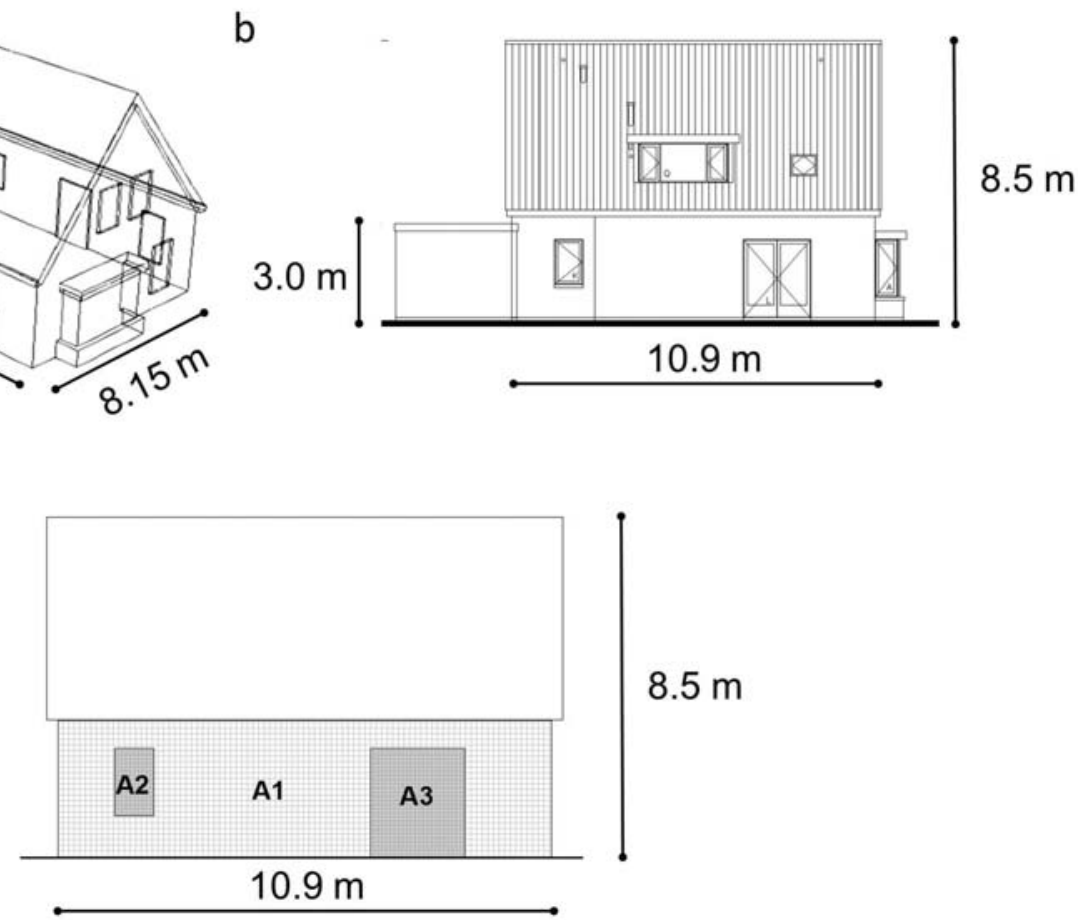

$.5 \mathrm{~m}$

Figure 12. Geometry of two-storey building with detached garage. (a) Perspective view; (b) View of south-west facade; (c) Indication of windows A2 and A3 on the south-west facade A1. 


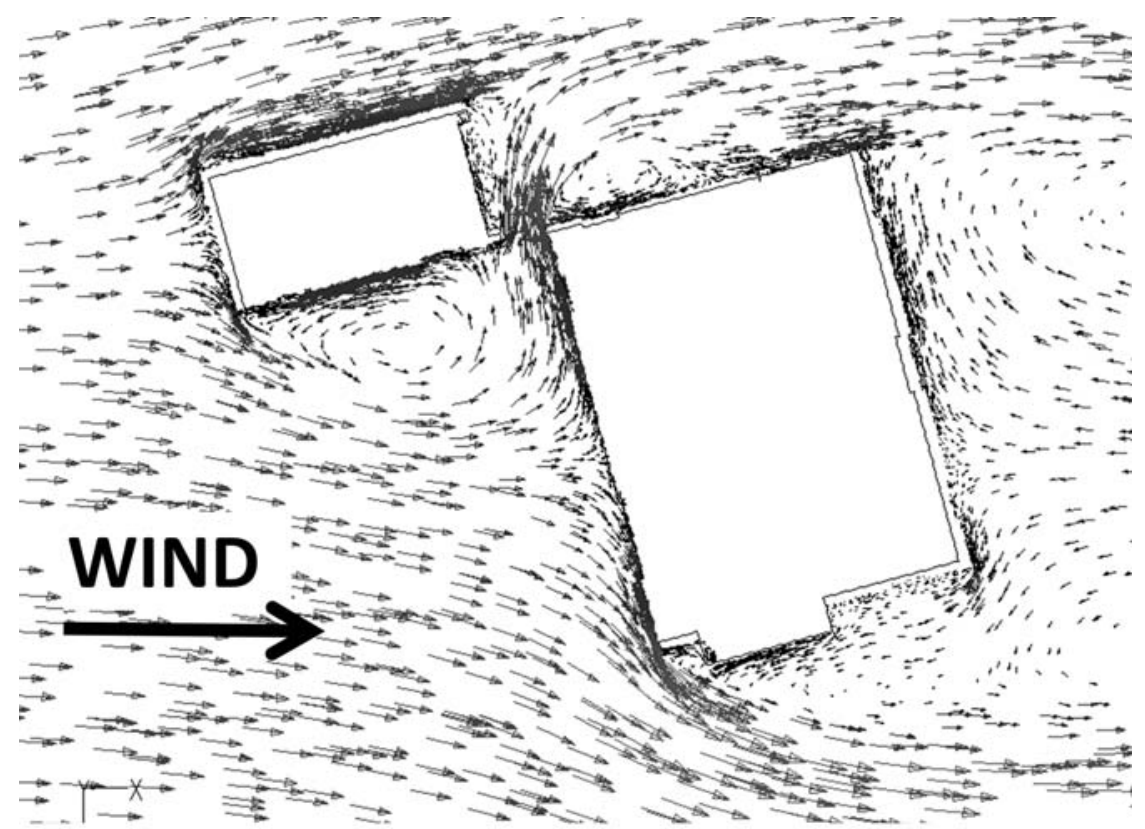

Figure 13. Mean wind-velocity vectors around the buildings, in a horizontal plane at a height of $1.75 \mathrm{~m}$.

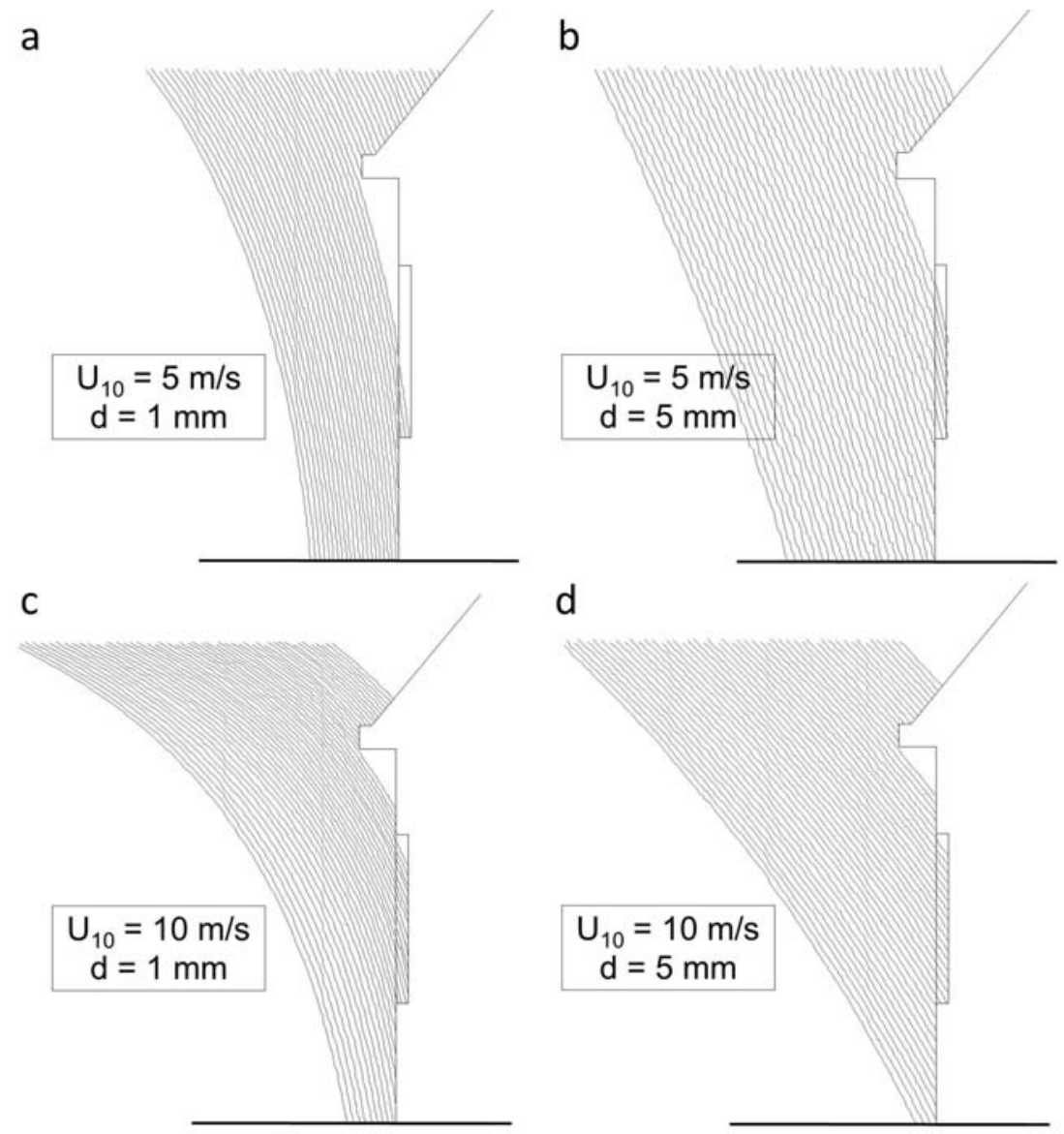

Figure 14. Raindrop trajectories for raindrop diameters $d=1$ and $d=5 \mathrm{~mm}$ and for wind speed $U_{10}=5 \mathrm{~m} / \mathrm{s}$ and $10 \mathrm{~m} / \mathrm{s}$. Note the shelter effect by the roof overhang and the window recession. 
a

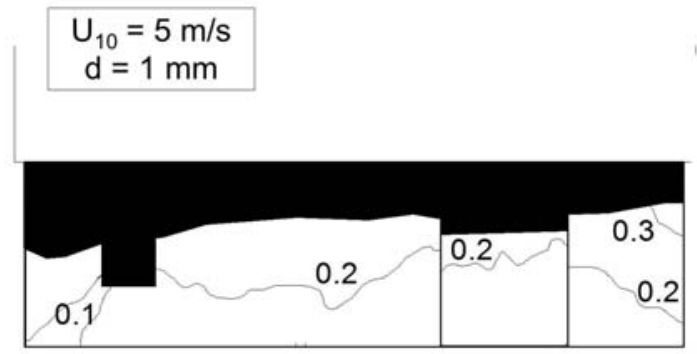

C

$$
\begin{gathered}
\mathrm{U}_{10}=10 \mathrm{~m} / \mathrm{s} \\
\mathrm{d}=1 \mathrm{~mm}
\end{gathered}
$$

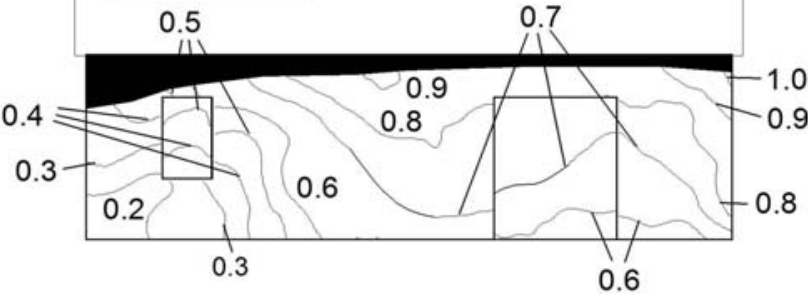

b

$$
\begin{gathered}
U_{10}=5 \mathrm{~m} / \mathrm{s} \\
d=5 \mathrm{~mm}
\end{gathered}
$$

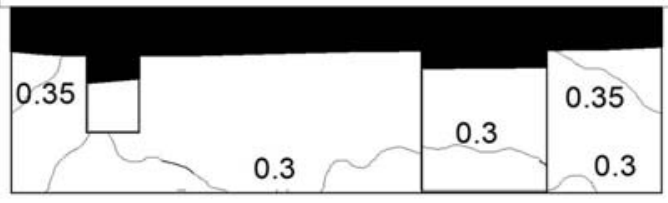

d

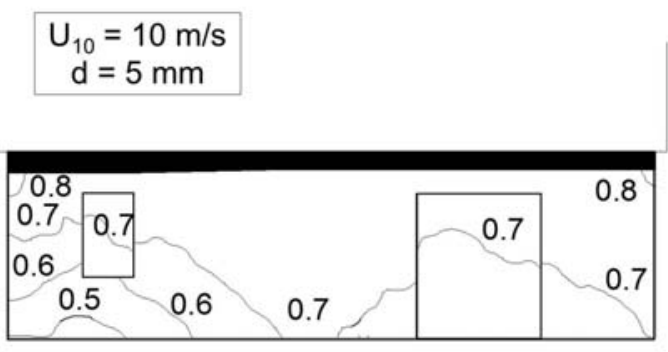

Figure 15. Specific catch ratio $\eta_{d}$ at the south-west facade for different values of wind speed $U_{10}(\mathrm{~m} / \mathrm{s})$ and raindrop diameter $\mathrm{d}(\mathrm{mm})$. The areas that are sheltered from rain are coloured black. 
a

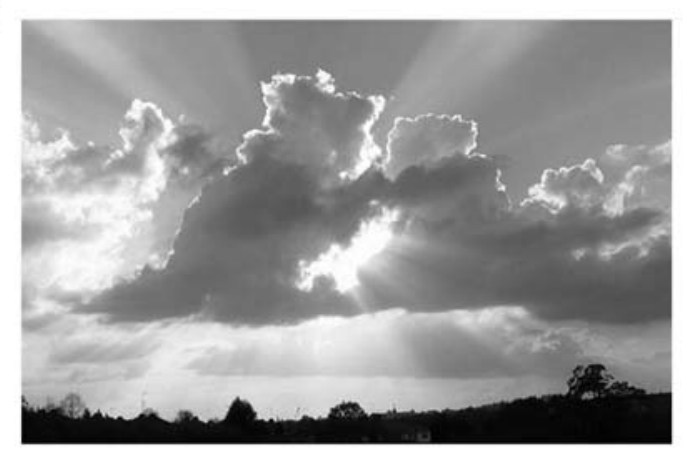

b

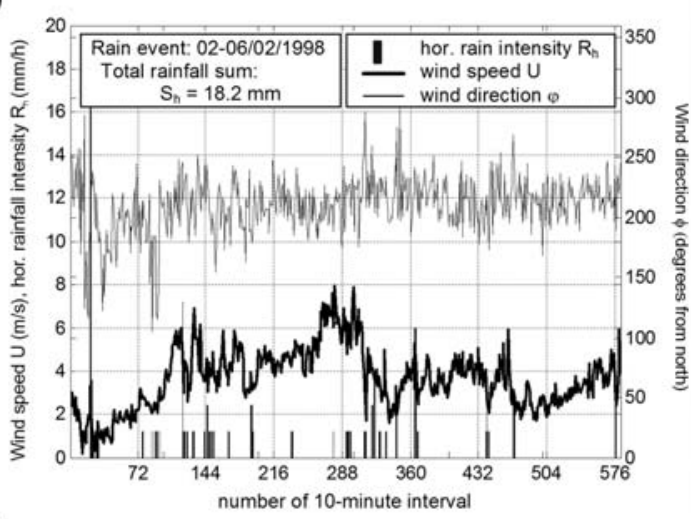

C

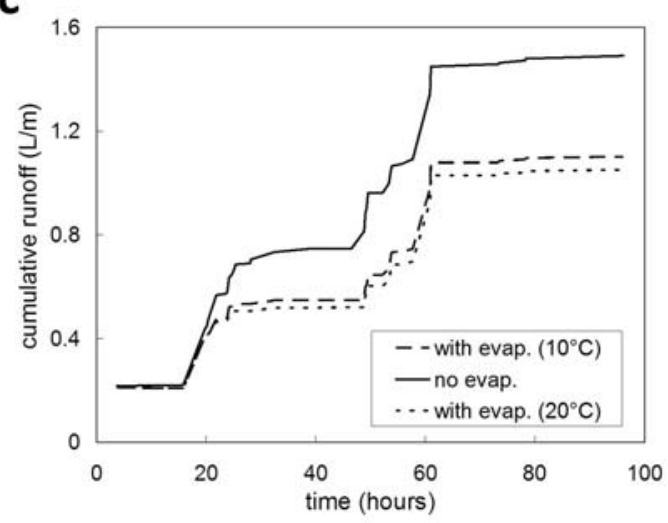

d

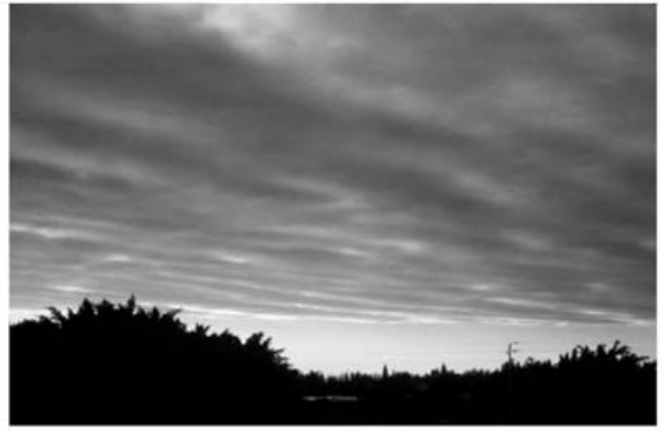

e

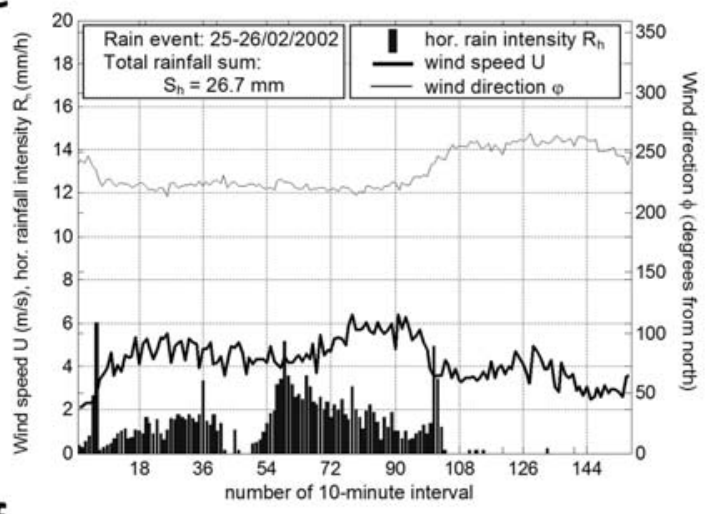

f

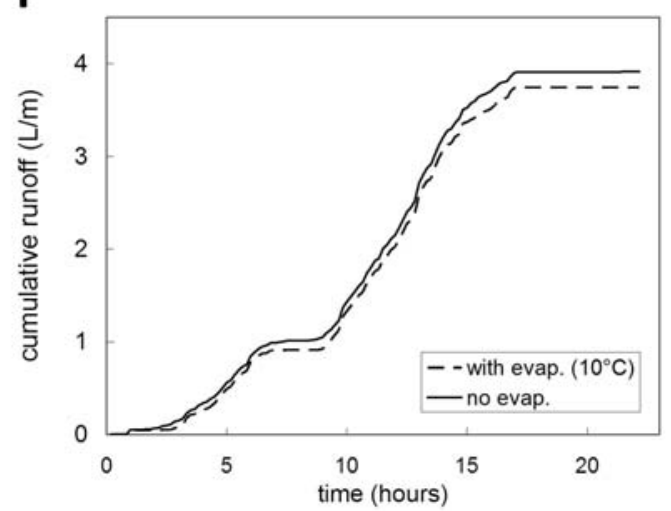

Figure 16. (a) Typical image of cumuliform clouds; (b) record of cumuliform rain event; (c) calculated cumulative amount of runoff (with and without evaporation) during the cumuliform rain event; (d) typical image of stratiform clouds; (e) stratiform rain event; (f) calculated cumulative amount of runoff (with and without evaporation) during the stratiform rain event. The measurements of the records in figures (b) and (d) were made at the site of the VLIET test building [29]. The calculations presented in figures (c) and (f) were made with typical measured values of relative humidity $\phi_{\mathrm{e}}=60 \%$ in dry periods and $90 \%$ during rain, and the given temperature. 